\title{
Enhanced permeation performance with incorporation of silver nitrate onto polymeric membrane
}

\author{
K. A. M. Said ${ }^{*}$, R.L. Jamain', N.S. M. Sutan², and N.A.M. Alipah¹ \\ ${ }^{1}$ Department of Chemical Engineering and Energy Sustainability, Faculty of Engineering, Universiti \\ Malaysia Sarawak, Kota Samarahan 94300, Malaysia \\ Phone: +6082583235; Fax: +6082583410 \\ ${ }^{2}$ Department of Civil Engineering, Faculty of Engineering, Universiti Malaysia Sarawak, 94300, \\ Kota Samarahan, Sarawak, MALAYSIA \\ *Email: mskanwar@unimas.my
}

\begin{abstract}
Enhancing membrane permeation is usually an important parameter in the membrane development for filtration. In this study, polysulfone membrane equipped with different concentration of silver nitrate (0.5-2.0 wt\%) were fabricated by phase inversion and later be known as composite membrane $(\mathrm{CM})$ followed by letter (A till $\mathrm{F}$ ) to indicate membrane composition. This study will investigate the effect of silver nitrate concentration to membrane permeation. Membrane morphology was investigated via scanning electron microscopy (SEM) and Fourier transform infrared spectroscopy (FTIR). Based on SEM examination, all composite membrane exhibits sponge-like structure otherwise FTIR for composite membrane with silver nitrate (CM B till CM E) shows additional peak at 1149.57 and 1294.24 indicating silver nitrate presence. In permeability test, composite membrane (CM C) with $1.0 \mathrm{wt} \%$ silver nitrate achieved $22.25 \mathrm{~L} / \mathrm{m}^{2}$.h of flux, the highest among all the composite membrane configuration. Thus, the result implied the addition of silver nitrate can increase permeation performance though excessive content may reduce the performance up to $50 \%$ of flux reduction. This work provides a better understanding of silver nitrate implication toward membrane permeability therefore provide an insight to any application of silver nitrate in membrane composition.
\end{abstract}

Keywords: Silver nitrate; Polyethyleneimine; Polysulfone; Flux; permeability.

\section{INTRODUCTION}

Water plays a very important role in life and usage span from domestic usage, power generation, agricultural activities and even tourism industries. However, one of the world most contributing environmental problem was associated with water i.e. polluted water basin or contaminated ground water all of which required more focused water treatments to meet the demand of clean water/potable water [1]. There are various techniques used for polluted water treatment such as precipitation of chemical agent [2-5], adsorption on activation carbon [4-8], ion-exchange on resins as well as membrane processes [9-15]. Albeit water is the main elements made up the earth, and accessible by us, but due to various activities happen surround it has causes the water to pollute. Thus, a well management of water development should be implemented in order to conserve and maintain the water quality. It has been a nature for us to take an action only after a really critical crisis happen. 
In water treatment technology, membrane separation received significant advancement in this recent years and mainly subjected to its ability to remove microbes, particles and even reducing water with high heavy metal [16]. Beside, membrane filtration has also been applied in the field of food processing [17-21], downstream process especially for biotechnology industry [22-25], seawater treatment or desalination process [24,26-30] and many other type of separations [17,3134]. The main reason of choosing membrane as part of the process were usually ease of operation, minimum waste generation and relatively low power needs [35].

However, there are drawbacks of choosing ultrafiltration (UF) and microfiltration (MF) due to their large pore size therefore allow passages of viruses and other nanoparticles as permeate. Moreover, any flaws on membrane surface or structure may also contribute to virus penetration. Therefore, in order to reduce risk of virus or other microorganism passing through the filtration process, several aids have been applied including ozone treatment and chlorination following filtration system. This extra process were installed in place to provide secondary antibacterial protection before water distribution or consumption [36]. In order to reduce the number of stages in tertiary treatment, researchers introduce membrane capable of antibacterial ability where the traditional polymeric membrane were given the ability to disinfect bacteria. Several type of additives with antibacterial properties has been tested over the years such as silver nitrate [37-40], chitosan [41-44], carbon nanotubes [41,45-47], graphene [48-52] and titanium dioxide [53-56].

Although in several occasion, the organic microfiltration and ultrafiltration able to remove the virus effectively without aids from pre or post-treatment. [57]. Any water sources contain high natural organic matter (NOM) may reduce significantly the membrane ability to filter and this phenomenon are known as membrane fouling. Membrane fouling is a major problem for membrane and usually lead to performance reduction and limit the effective area of membrane. [16].

The few factors that define a membrane's effectiveness are permeability, pore structure, selectivity, hydrophilicity, and mechanical stability As for permeability which mostly affected by fouling can be control by introducing nanoparticles to altered the membrane structure[58]. Besides that, polymeric membranes are favored for their ease of fabrication and their low cost [59], however, their disadvantages are that the polymers most commonly used, namely polysulfone (PSU) which are semi-hydrophobic which can lead to reduced flux and increased fouling [60] but the polyethyleneimine had been used in this study to increase the hydrophilicity with the adding of silver nanoparticles. Silver is another commonly used nanoparticle for nanocomposite membranes: silver nanoparticles are widely known to be antimicrobial, and there are commercial home water systems currently available which use membranes or filters coated with silver nanoparticles, and these are reported to remove $99.99 \%$ of pathogens[47]. They have also been shown recently to improve hydrophilicity in polymeric membranes [61] and change the porous structure of membranes [62].

Polyethyleneimine (PEI) can be used as a stabilizing agent and reducing agent [63]. In this study PEI was used as stabilizing agent for silver nanoparticles formation. As stabilizing agent, PEI will provide increase in hydrophilicity, lowering non-intended adsorption and increase water solubility of the membrane. [60,61]. Despite the ability to increase membrane permeability, PEI also consist of cationic charge that can react with heavy metal ion either in basic or acidic environment to form a complex coordination [66]. Nevertheless, the ability of PEI modifying the membrane morphology has not been study in-depth providing more area or function for further exploration. [67].

For the preparation of ultrafiltration membrane, polysulfone (PSU) are usually the popular choice of polymer among fabricator due to its abilities to withstand heat and easy to form [68]. However, there are several limitation of polysulfone as membrane polymer for instances it hydrophobic properties will result in reduced water flux making it susceptible to fouling [69]. Thus, 
several methods have been developed for reducing polysulfone hydrophobicity and the most notable are by blending polysulfone with hydrophilic polymer. Furthermore, several metal has shown ability to modified membrane structure by suppressing hydrophobic properties including silver, copper and zinc, apart from that giving the membrane added value for example antibacterial properties [18].

Despite polysulfone hydrophobic properties, it still popularly used in the applications of pharmacy, biology and medicine due to its high stability on a variety of methods. The advantages of PSU are high rigidity, stability and creep resistance. Besides, it also exhibits good thermal stability. Thus, several works has been proposed to modified polysulfone membrane with aim to reduce the tendency of membrane foulants as well as improving other properties [70]. These studies involve on the addition of additive, composition formulation, processing variables as well as the study of kinetic and thermodynamic phase inversion. Among these modification techniques, addition of additive is widely used for membrane making[62].

In this work, silver nitrate is selected as additive that will be introduced into PSU to form mixed matrix membrane. The present effort focuses on the improving flux of PSU-based membrane by incorporating $\mathrm{AgNO}_{3}$ and NMP. It is expected that the addition of such materials will not only improve membrane separation performance but also will create synergetic effect towards improving membrane permeation leading to high flux.

\section{EXPERIMENTAL SET UP}

\section{Material}

Polysulfone (PSU) pellets (PSU with $\mathrm{MW}=35 \mathrm{kDa}$ ) and polyethylenimine (PEI) branched (PEI with $\mathrm{MW}=25 \mathrm{kDa}$ ) were purchased from Sigma-Aldrich Trading Co., Ltd. (USA), used as polymer for the membrane fabrication. PEI was supplied with low mol. wt., 50 wt. \% solution in water. The solvent for PSU pellets is $99.5 \%$ of N-Methyl-2-pyrrolidone (NMP) was obtained from Sigma-Adrich Trading Co., Ltd. (USA). Powdered activated carbon (AC) was purchased from Norit Americas, Inc. (USA). 98\% of Silver Nitrate (AgNO3) was supplied from Merck (Germany). The distilled water was used as the non-solvent for the polymer precipitation.

\section{Preparation of membrane}

The flat sheet polysulfone (PSU) membranes are prepared by using a wet phase inversion method. According to [71], 0.3wt $\%$ of PEI, 15\% PSU and $0.5 \mathrm{wt} \%$ AC were solubilize in NMP (85 wt \%) and the solution was magnetically stir for $7 \mathrm{~h}$ to form a homogenous solution at $40{ }^{\circ} \mathrm{C}$. The lid of the container was kept close to prevent the solvent loss due to evaporation during the whole stirring process $(360 \mathrm{rpm})$. Figure 1 shows the schematic illustration to prepare a flat sheet membrane.

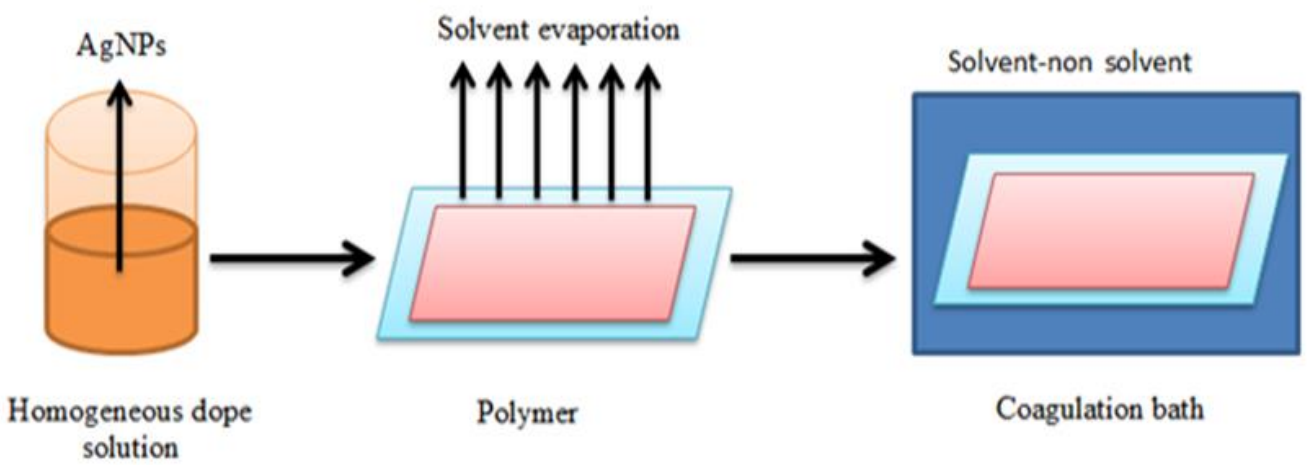

Figure 1. Schematic illustration of membrane preparation. 
Then, the different amounts of silver nitrates $\left(\mathrm{AgNO}_{3}\right)$ were separately dissolved in $3.0 \mathrm{ml}$ of NMP. These solutions were added to the PSU solution in order to obtain different silver nanoparticles (AgNP) content membrane casting solutions. NMP was acts as a reducing agent for the formation of the AgNP. Table 1 shows the composition of all the membranes preparation in this research. The amount of polymer, NMP and $\mathrm{AC}$ were kept constant and only the amount of $\mathrm{AgNO}_{3}$ was varied.

Table 1. Composition of all the membranes.

\begin{tabular}{cccccc}
\hline \multirow{2}{*}{$\begin{array}{c}\text { Membrane } \\
\text { type }\end{array}$} & \multicolumn{5}{c}{ Composition (wt \%) } \\
\cline { 2 - 6 } $\mathrm{AgNO}_{3}$ & PSU & PEI & NMP & AC \\
\hline CM A & - & 15.0 & - & 85.0 & - \\
CM B & 0.5 & 15.0 & 0.3 & 83.7 & 0.5 \\
CM C & 1.0 & 15.0 & 0.3 & 83.2 & 0.5 \\
CM D & 1.5 & 15.0 & 0.3 & 82.7 & 0.5 \\
CM E & 2.0 & 15.0 & 0.3 & 82.2 & 0.5 \\
CM F & - & 15.0 & 0.3 & 84.2 & 0.5 \\
\hline
\end{tabular}

\section{FTIR analysis}

Fourier Transform Infrared Spectroscopy (FTIR) (Bunker Equinox 50) analysis is used to study the functional changes that occur in composite membrane. The analysis only requires small pieces of the composite membrane. The FTIR spectra obtained is in the range 4000 to $400 \mathrm{~cm}^{-1}$ with 40 scans per sample and $4 \mathrm{~cm}^{-1}$ resolutions. The presence of the functional groups available in the membranes are represented by the transmittance value at specific wavelength.

\section{SEM analysis}

Scanning Electron Microscopy (SEM) is an imaging technique utilizing energy beam in which producing a pattern in the form of raster scan where electron from the beam interact with atom on the surface of sample. Later, the interaction of electron-atom will eventually turn to signal that correspond to information of the sample surface or its cross section. The surface morphology and the cross-section of the membrane samples were characterized and examined using JEOL JSM6390LAoperated at $15 \mathrm{kV}$. Prior to imaging, membrane was cut into small squares approximately $1 \mathrm{~cm}^{2}$ before fractured in liquid nitrogen for a clean break. Before fractured process, membrane was left inside the liquid nitrogen chamber for 1 minute and transfer to sample stub after a successful fractured process. Then, the prepared samples were sputtered with a layer of gold coating using JOEL Fine Auto to increase electron-atom interaction that may as well affect imaging process of SEM. Later, membrane surface morphology as well as cross section were observed to study the effect of silver nitrate addition to its structure.

\section{Permeation test}

The performance of the membrane was characterized by measuring the membrane flux dead-end filtration system; AMICON Ultrafiltration Cell (Model 8050, Millipore Corp., Bedford, MA) with a total internal volume of $50 \mathrm{ml}$ and active surface area of $13.4 \mathrm{~cm}^{2}$. First, the membrane with radius of $44.5 \mathrm{~mm}$ was soaked in the deionized water to facilitate the filtration process for 30 minutes. Then, the soaked membrane was placed at membrane holder and sealed with O-ring to avoid leaking during operation. The deionized water was used as feed solution. A magnetic stirrer was placed under the membrane cell to stir the feed. The flux of membranes was measured during 10 
minutes' filtration and compact at 1 bar $(\mathrm{g})$. The permeate was continuously monitored by collecting the discharged within the regular interval followed by volume measurement. The experiments are carry out at room temperature and the pressure of 2 bar provided by compress gas. The membranes fluxes were calculated as follows based on Eq.(1) by [61]:

$$
\mathrm{J}_{\mathrm{o}}=\mathrm{Q} / \mathrm{A} \Delta \mathrm{t}
$$

where $J_{0}$ is pure water flux $\left(L \cdot \mathrm{m}^{-2} \mathrm{~h}^{-1}\right), \mathrm{Q}$ is the permeate volume $(L), \mathrm{A}$ is the membrane area $\left(\mathrm{m}^{2}\right)$ and $\Delta \mathrm{t}$ is the time $(\mathrm{h})$.

\section{FTIR Analysis}

\section{RESULTS AND DISCUSSION}

FTIR analysis was important to monitor any changes in functional group with addition of silver nitrate. Table 2 shows the FTIR spectra for sample CM A, CM E and CM F. The obvious changes of peak clearly shown in the membrane sample CM A, CM E and CM F, since there are different materials present as mentioned in Table 1. From the spectra of CM A, CM E and CM F, it were clearly showed the peak of $873.75 \mathrm{~cm}^{-1}$ which resemble the $\mathrm{C}-\mathrm{H}$ aromatic correspond to out-plane deformation [72].

As shown in Figure 2, CM A exhibit C-N stretching at $1319.31 \mathrm{~cm}^{-1}$ from the strong absorption of imide group. After the additional of PEI, the sample of CM E and CM F show sharper peak at $1623 \mathrm{~cm}^{-1}$ ( $\mathrm{C}=\mathrm{O}$ stretching). This observation comply with the study of Goa et al., (2014) who found the amide group after PEI cross linking with PSU membrane [73]. Both CM E and CM F show strong absorption peaks at $1585.49 \mathrm{~cm}^{-1}$ that associated with $\mathrm{N}-\mathrm{H}$ bond, $2310.72 \mathrm{~cm}^{-1}$ corresponding to $\mathrm{NH}^{+}$asymmetric stretching vibration compared to $\mathrm{CM} A$ due to the addition of PEI into the composite membranes as PEI is a composed of the amine group on the repeating unit. The results obtained showed the same observation with the addition of PEI [74].

Table 2. Peak position of CM A till CM F.

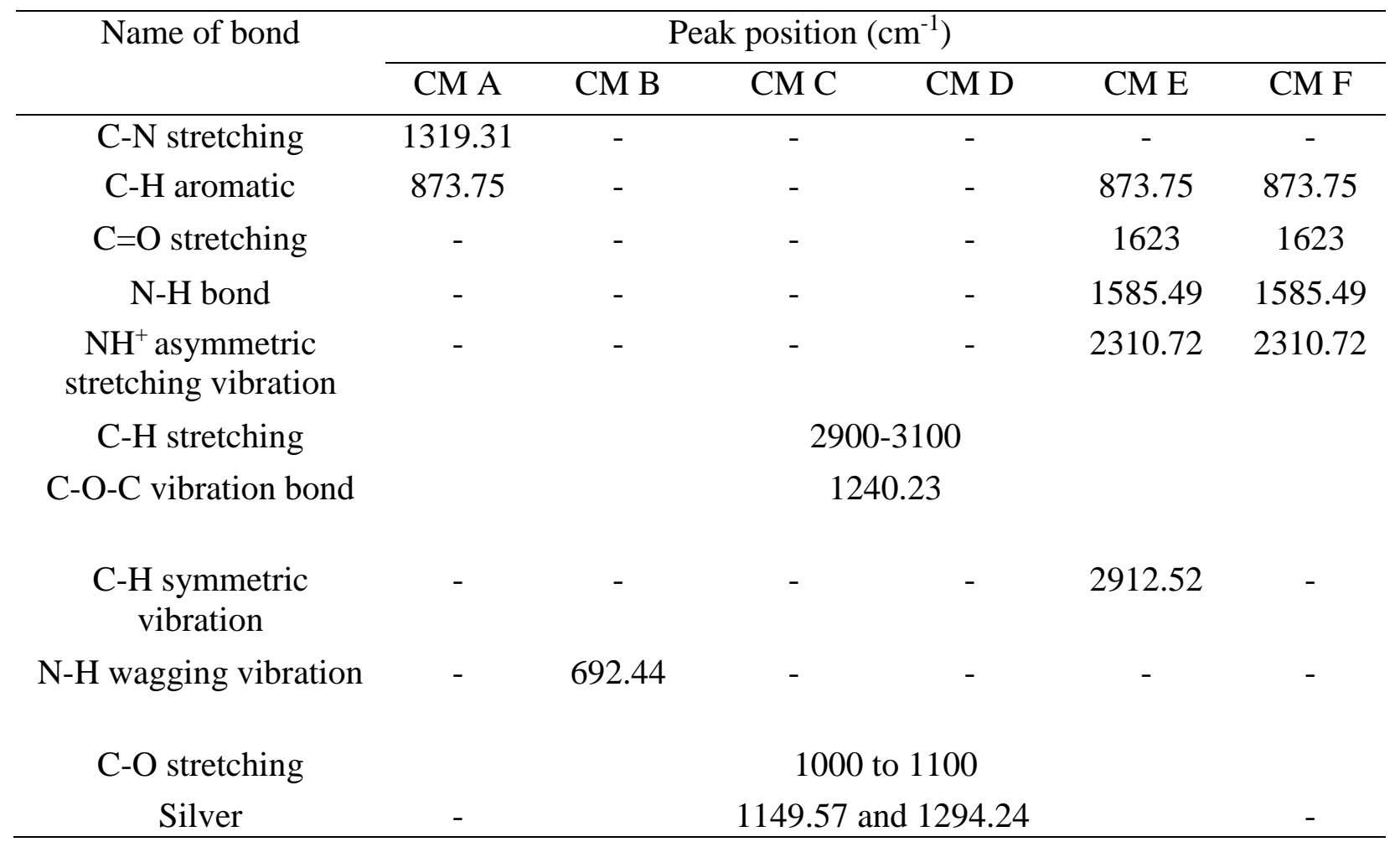


All composite membrane has similar spectrum characteristics since they comprise of same materials which are PSU/PEI/NMP/AgNO $/$ AC. The peaks between $2900 \mathrm{~cm}^{-1}$ and $3100 \mathrm{~cm}^{-1}$ are represent as aromatic and aliphatic $\mathrm{C}-\mathrm{H}$ stretching vibration [4,20]. All membranes exhibit $\mathrm{C}-\mathrm{O}-\mathrm{C}$ vibration bond at peak $1240.23 \mathrm{~cm}^{-1}$. The peak of $2912.52 \mathrm{~cm}^{-1}$ indicates the present of $\mathrm{C}-\mathrm{H}$ symmetric vibration that responsible for alkyl groups [75]. Characteristic band at $692.44 \mathrm{~cm}^{-1}$ indicate $-\mathrm{NH}$ wagging vibration [74]. The peaks at 1149.57 and $1294.24 \mathrm{~cm}^{-1}$ represent symmetric stretching vibration of $\mathrm{O}=\mathrm{S}=\mathrm{O}$ group of PSU membrane. As shown in Table 2, both peaks at $1149.57 \mathrm{~cm}^{-1}$ and $1294.24 \mathrm{~cm}^{-1}$ become sharper with increasing of silver concentration [69].

\section{Membrane Morphology}

Figure 2 shows the surface morphology of membrane taken by SEM imaging with CM (A - F) refer to different composition of the membrane specifically silver nitrate content. CM A, displayed a rough surface and the membrane pores cannot be clearly seen due to high roughness as shown in Figure 4 (a). The previous study found pure PSU also exhibited rough surface morphology based on the observations $[4,8]$. Same result of rough surface exhibited by CM F as shown in Figure 4 (f), where it does not contain silver. The addition of silver to the composite membranes become smoother compared to CM A and CM F. All membranes show similar flat surfaces without obvious aggregation on membrane surface.

The cross-section morphologies changes in composite membrane shown in Figure 3. All the composite membrane exhibits the typical symmetric structure with sponge like structure. In the finding of [70], extensive diffusion caused by hydrogen bonding of the non-solvent with membrane functional group as well as hydrophilic properties of PEI has changed the membrane structure to sponge-like formation [74].
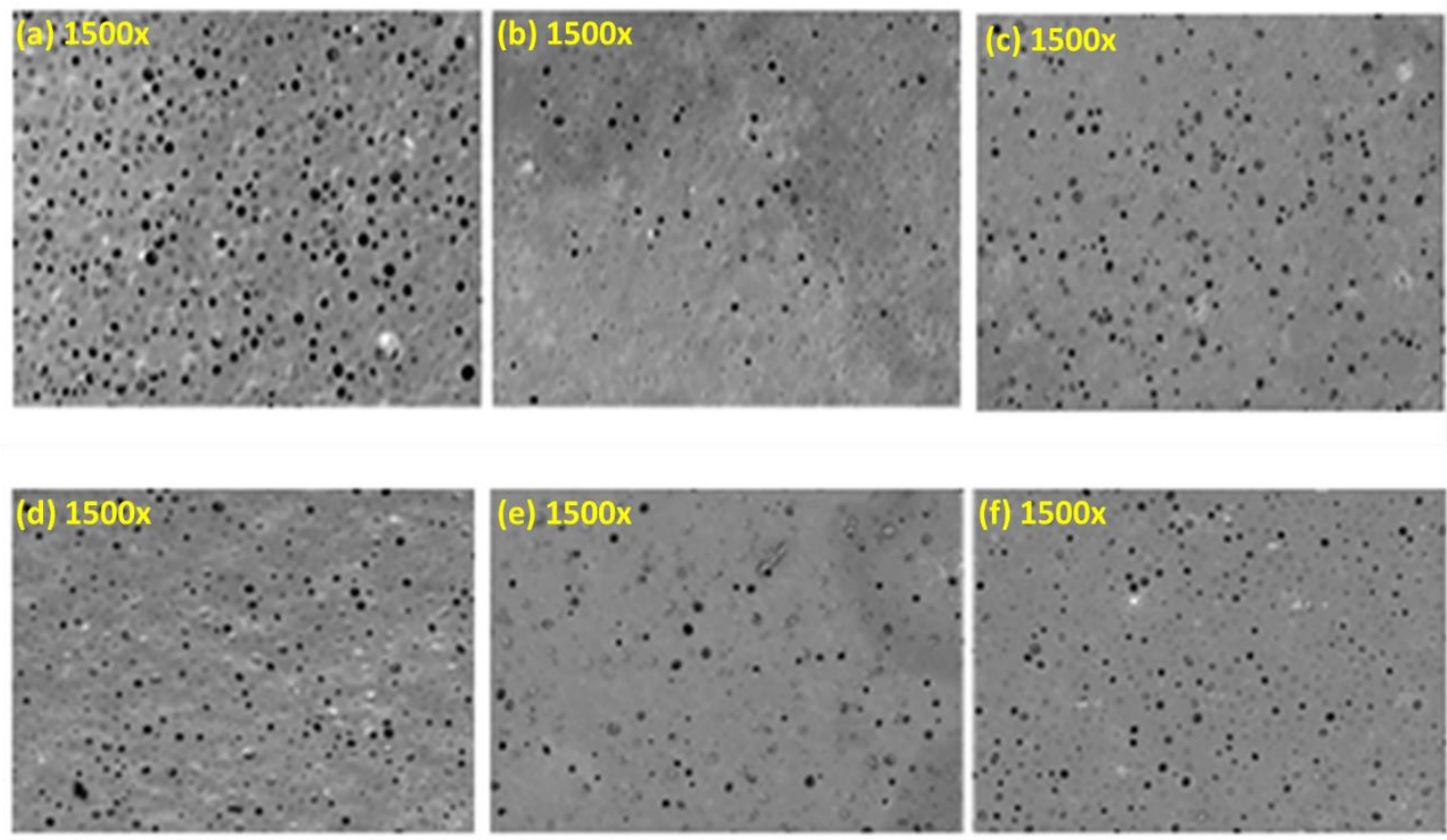

Figure 2. SEM image for surface morphology (1500 magnification, $50 \mu \mathrm{m}$ ) (a) pure PSU membrane, (b) $0.5 \mathrm{wt} \%$ silver content, (c) $1.0 \mathrm{wt} \%$ silver content, (d) $1.5 \mathrm{wt} \%$ silver content, (e) $2.0 \mathrm{wt} \%$ silver content and (f) $0 \mathrm{wt} \%$ silver content. 

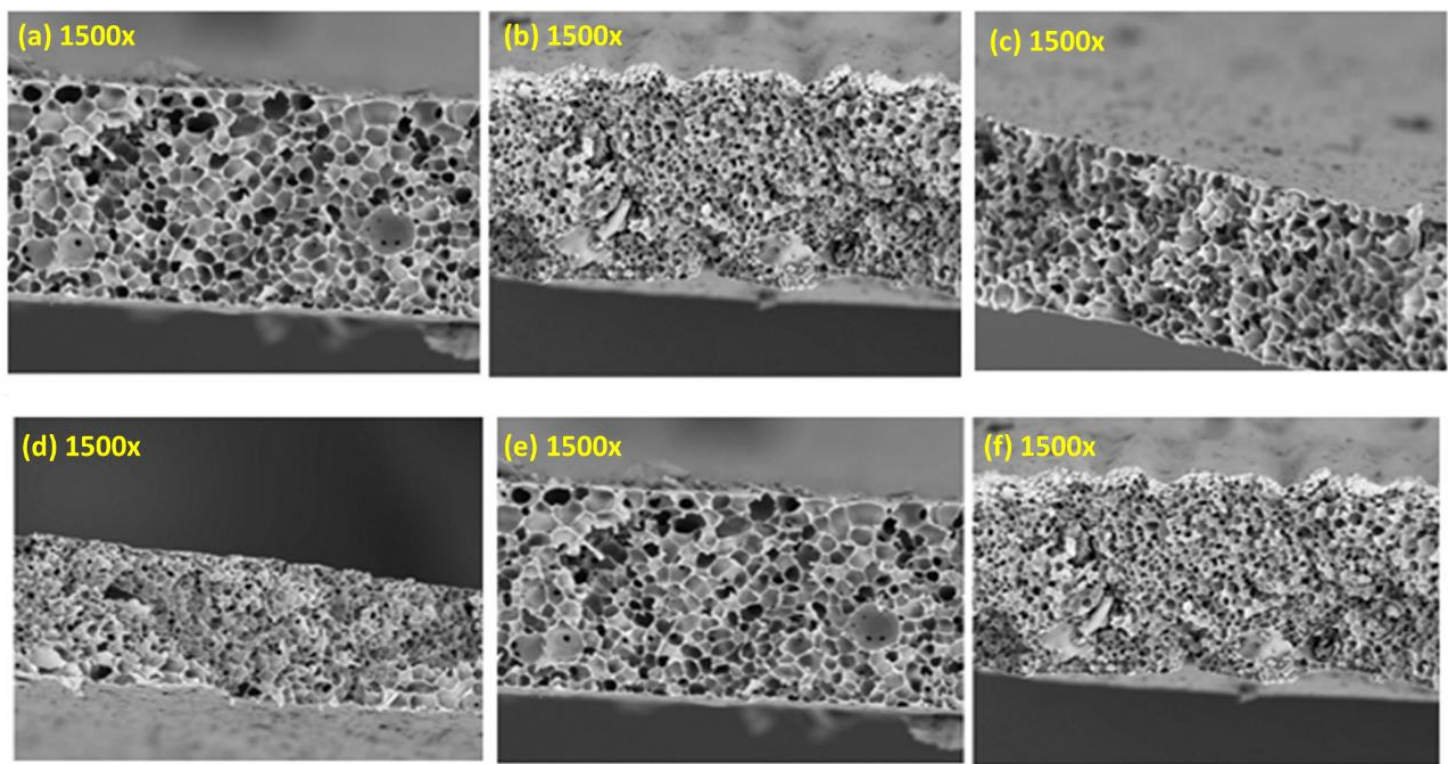

Figure 3. SEM image for cross section morphology (1500 magnification, $50 \mu \mathrm{m}$ ) (a) pure PSU membrane, (b) $0.5 \mathrm{wt} \%$ silver content, (c) $1.0 \mathrm{wt} \%$ silver content, (d) $1.5 \mathrm{wt} \%$ silver content, (e) $2.0 \mathrm{wt} \%$ silver content and (f) $0 \mathrm{wt} \%$ silver content.

The second region as illustrated in Figure 3 shows the porous layer of the membrane. The addition of different amount of silver ions in the composite membrane shows small changes in the cross-section morphology. As silver concentration in composite membranes increased, the viscosity of the casting solution also increased due to increased nanoparticle or polymer ratio. The viscosity of casting solution plays major part in phase inversion because it affects the solvent-nonsolvent exchange rate as well as morphology of the membranes [76]. The addition of silver nitrate could promote the formation of macrovoids in the membrane. There were no macro voids on the cross section of membrane as observed from Figure 3 (a) due to the pure PSU membrane morphology. However, as an antibacterial agent contents increased to $2.0 \mathrm{wt} \%$ (CM E), the macro voids clearly shown in Figure 3 ( $d$ and e). Meanwhile, there appeared more effective pores on the top surface of CM D and CM E membranes, which became small and uniform. Similar observations were obtained from previous study observed cross-section morphology of composite membranes displayed macro voids at the bottom as the addictive percentage increased and [48] found macrovoids were expanded in number and size with increasing the amount of silver [23, 27].

\section{Membrane Flux}

For any membrane filtration process, water permeability is the most important parameter in determining the performance of the membrane. The pure water fluxes of the membranes with respect to different stages of modification are shown in Figure 4. Stirred Ultrafiltration Cell was used to study the flux of composite membrane with different silver loading. The flux is used to express the rate at which water permeates a membrane barrier $\left(\mathrm{L} / \mathrm{m}^{2} . \mathrm{h}\right)$. The change in permeability is presented to demonstrate the effect of modification. 


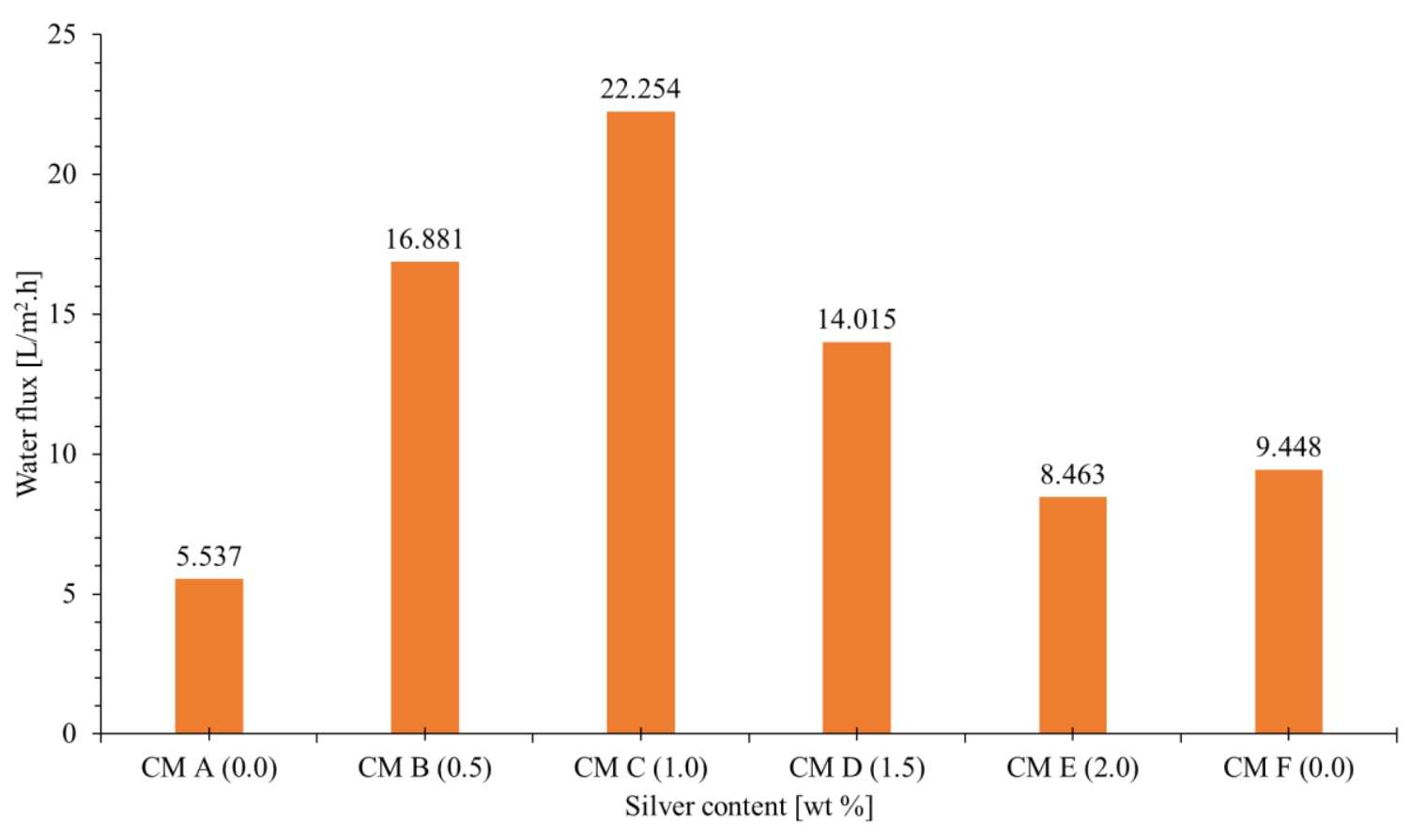

Figure 4. Flux Changes of the Composite Membranes.

From Figure 4, CM A to CM C shows increments of pure water flux of $5.5371 \mathrm{~L} / \mathrm{m}^{2} . \mathrm{h}$, $16.8806 \mathrm{~L} / \mathrm{m}^{2}$.h to $22.2537 \mathrm{~L} / \mathrm{m}^{2}$.h with increasing $\mathrm{AgNO}_{3}$ concentration $(0 \mathrm{wt} \%, 0.5 \mathrm{wt} \%$ and 1.0 wt\% respectively). These shows that the addition of silver into composite membrane provide better water flux performance when compared to CM A by $67.20 \%$ for CM B and $75.11 \%$ for CM C (highest water flux). This can be explained by the increase in hydrophilicity of the membranes which could attract water molecule to pass through them [18]. Further addition of $\mathrm{AgNO}_{3}$ concentration ( $1.5 \mathrm{wt} \%$ and $2.0 \mathrm{wt} \%$ ), the flux then reduced to $14.0149 \mathrm{~L} / \mathrm{m}^{2} . \mathrm{h}$ and $8.4627 \mathrm{~L} / \mathrm{m}^{2} . \mathrm{h}$ respectively.

Previous research showed that by increasing the concentration of silver nanoparticles on the membrane resulting low water flux due to barrier created by the presence of silver nanoparticles or agglomeration of nanoparticles on the membrane surface $[2,25]$. The agglomeration of the silver occurs due to the formation of crystalline silver particle in this research which leads to low water permeate. This observation was in agreement with the study of where the addition of silver nitrate in the dope solution attributed to the high crystallinity of silver nanoparticle [78]. The pure water flux for CM F was higher than CM A due to additional of PEI which increase the membrane hydrophilicity compared to CM A.

Surface pore size, cross-section morphology, skin layer thickness, and hydrophilicity contribute to a membrane's permeability [79] and rejection properties, and in nanocomposite mixed matrix membranes (MMMs) [80], surface modification with nano-sized particles is used to alter these membrane properties. In this study, the Ag-PSU/PEI membranes were successfully fabricated. Ag-PSU/PEI mixed ultrafiltration membrane with good hydrophilicity performance was prepared via phase inversion method. Morphologies and filtration performance of the mixed membrane were investigated. The morphologies of mixed membrane were improved significantly, where the porosity and pore size played a great role in the filtration of membranes. The pure water flux of blended membrane with $0.5 \%$ of Ag-PSU/PEI hybrid membrane was four times higher than that of the pure PSU membrane. 


\section{CONCLUSIONS}

The following conclusion was derived based on the effect of silver nitrate to membrane structure and performance:

1. Addition of silver nitrate into membrane has effect on membrane structure specifically reducing the pore size and forming a dense and sponge membrane formation.

2. All membrane with silver nitrate has shown increased in water flux with the highest flux recorded for $1.0 \mathrm{wt} \%$ of silver nitrate.

Based on the findings, it is now known that addition of silver nitrate has affected the membrane morphology and directly responsible to the increased of membrane water flux. The significant of this findings towards industrial process and application would be the major effect of silver nitrate onto membrane other than to introduce antibacterial effect was increasing the membrane flux through formation of macro-void.

\section{ACKNOWLEDGEMENTS}

This works was fully funded by Fundamental Research Grant Scheme (FRGS), FRGS/TK04(03)/1140/2014(07). All authors would like to express our gratitude to Ministry of Higher Education (MOHE) and Universiti Malaysia Sarawak (UNIMAS) for the grant approval as well as for the facilities to run this experiment.

\section{REFERENCES}

[1] Wibowo E, Rokhmat M, Sutisna, Khairurrijal, Abdullah M. Reduction of seawater salinity by natural zeolite (Clinoptilolite): Adsorption isotherms, thermodynamics and kinetics. Desalination 2017; 409(1 May 2017): 146-56.

[2] Byrne C, Subramanian G, Pillai SC. Recent advances in photocatalysis for environmental applications. Journal of Environmental Chemical Engineering 2017; 6(3): 3531-55.

[3] Ahmed S, Rasul MG, Martens WN, Brown R, Hashib MA. Heterogeneous photocatalytic degradation of phenols in wastewater: A review on current status and developments. Desalination 2010; 261(1-2): 3-18.

[4] Warsinger DM, Chakraborty S, Tow EW, Plumlee MH, Bellona C, Loutatidou S, Karimi L, Mikelonis AM, Achilli A, Ghassemi A, Padhye LP, Snyder SA, Curcio S, Vecitis C, Arafat HA, Lienhard JH. A review of polymeric membranes and processes for potable water reuse. Progress in Polymer Science 2018; 81(June 2018): 209-37.

[5] Soni U, Bajpai J, Singh SK, Bajpai AK. Evaluation of chitosan-carbon based biocomposite for efficient removal of phenols from aqueous solutions. Journal of Water Process Engineering 2017; 16(April 2017): 56-63.

[6] Nor NAM, Jaafar J, Ismail AF, Mohamed MA, Rahman MA, Othman MHD, Lau WJ, Yusof $\mathrm{N}$. Preparation and performance of PVDF-based nanocomposite membrane consisting of $\mathrm{TiO} 2$ nanofibers for organic pollutant decomposition in wastewater under UV irradiation. Desalination 2016; 391(1 August 2016): 89-97.

[7] Mukherjee S, Basak B, Bhunia B, Dey A, Mondal B. Potential use of polyphenol oxidases (PPO) in the bioremediation of phenolic contaminants containing industrial wastewater. Reviews in Environmental Science and Biotechnology 2013; 12(1): 61-73.

[8] Ong CS, Lau WJ, Goh PS, Ng BC, Ismail a. F. Preparation and characterization of PVDFPVP-TiO 2 composite hollow fiber membranes for oily wastewater treatment using 
submerged membrane system. Desalination and Water Treatment 2013(September 2014): 111.

[9] Masoumi A, Ghaemy M. Removal of metal ions from water using nanohydrogel tragacanth gum-g-polyamidoxime: Isotherm and kinetic study. Carbohydrate Polymers 2014; 108(1): 206-15.

[10] Kaner P, Rubakh E, Kim DH, Asatekin A. Zwitterion-containing polymer additives for fouling resistant ultrafiltration membranes. Journal of Membrane Science 2017; 533(1 July 2017): 141-59.

[11] Goh PS, Lau WJ, Othman MHD, Ismail AF. Membrane fouling in desalination and its mitigation strategies. Desalination 2018; 425(August 2018): 130-55.

[12] Carolin CF, Kumar PS, Saravanan A, Joshiba GJ, Naushad M. Efficient techniques for the removal of toxic heavy metals from aquatic environment: A review. Journal of Environmental Chemical Engineering 2017; 5(3): 2782-99.

[13] Phelane L, Muya FN, Richards HL, Baker PGL, Iwuoha EI. Polysulfone Nanocomposite Membranes with improved hydrophilicity. Electrochimica Acta 2014; 128(10 May 2014): 326-35.

[14] Owoeye FT, Azodo AP, Udo SB. Performance Evaluation of Ceramics Microfiltration Membrane for Water Treatment. Journal of Mechanical Engineering and Sciences 2014; 7(December): 2289-4659.

[15] Mohamad S, Abdullah H, Idris M, Harun Z, Ismail A, Yunos M, Hasan S. Influence of Polyethylene Glycol Additive on Performance of Polysulfone and Polyethersulfone Membrane. Journal of Mechanical Engineering and Sciences 2014; 6(June 2014): 746-52.

[16] Sawada I, Fachrul R, Ito T, Ohmukai Y, Maruyama T, Matsuyama H. Development of a hydrophilic polymer membrane containing silver nanoparticles with both organic antifouling and antibacterial properties. Journal of Membrane Science 2012; 387-388(1 January 2012): $1-6$.

[17] Cassano A, De Luca G, Conidi C, Drioli E. Effect of polyphenols-membrane interactions on the performance of membrane-based processes. A review. Coordination Chemistry Reviews 2017; 351(15 November 2017): 45-75.

[18] Chen Y, Zhang Y, Liu J, Zhang H, Wang K. Preparation and antibacterial property of polyethersulfone ultrafiltration hybrid membrane containing halloysite nanotubes loaded with copper ions. Chemical Engineering Journal 2012; 210(1 November 2012): 298-308.

[19] Park MJ, Phuntsho S, He T, Nisola GM, Tijing LD, Li XM, Chen G, Chung WJ, Shon HK. Graphene oxide incorporated polysulfone substrate for the fabrication of flat-sheet thin-film composite forward osmosis membranes. Journal of Membrane Science 2015; 493(1 November 2015): 496-507.

[20] Imbrogno J, Keating JJ, Kilduff J, Belfort G. Critical aspects of RO desalination: A combination strategy. Desalination 2017; 401(2 January 2017): 68-87.

[21] Zhang M, She Q, Yan X, Tang CY. Effect of reverse solute diffusion on scaling in forward osmosis: A new control strategy by tailoring draw solution chemistry. Desalination 2017; 401(2 January 2017): 230-7.

[22] Chung TS, Luo L, Wan CF, Cui Y, Amy G. What is next for forward osmosis (FO) and pressure retarded osmosis (PRO). Separation and Purification Technology 2015; 156(17 December 2015): 856-60.

[23] Liao Y, Loh C-H, Tian M, Wang R, Fane AG. Progress in electrospun polymeric nanofibrous membranes for water treatment: fabrication, modification and applications. Progress in Polymer Science 2017; 77(February 2018): 69-94.

[24] Ali A, Tufa RA, Macedonio F, Curcio E, Drioli E. Membrane technology in renewable- 
energy-driven desalination. Renewable and Sustainable Energy Reviews 2018; 81(July 2017): 1-21.

[25] Yi S, Su Y, Qi B, Su Z, Wan Y. Application of response surface methodology and central composite rotatable design in optimizing the preparation conditions of vinyltriethoxysilane modified silicalite/polydimethylsiloxane hybrid pervaporation membranes. Separation and Purification Technology 2010; 71(2): 252-62.

[26] Lin S, Elimelech M. Kinetics and energetics trade-off in reverse osmosis desalination with different configurations. Desalination 2017; 401(2 January 2017): 42-52.

[27] Safaei S, Tavakoli R. On the design of graphene oxide nanosheets membranes for water desalination. Desalination 2017; 422(15 November 2017): 83-90.

[28] Turek M, Mitko K, Piotrowski K, Dydo P, Laskowska E, Jakbik-Kolon A. Prospects for high water recovery membrane desalination. Desalination 2017; 401(2 January 2017): 180-9.

[29] Goh PS, Ismail AF. A review on inorganic membranes for desalination and wastewater treatment. Desalination 2017; 434(15 May 2018): 60-80.

[30] Salmón IR, Luis P. Membrane crystallization via membrane distillation. Chemical Engineering and Processing: Process Intensification 2017; 123(January 2018): 258-71.

[31] Cheng X, Liang H, Ding A, Tang X, Liu B, Zhu X, Gan Z, Wu D, Li G. Ferrous iron/peroxymonosulfate oxidation as a pretreatment for ceramic ultrafiltration membrane: Control of natural organic matter fouling and degradation of atrazine. Water Research 2017; 113(15 April 2017): 32-41.

[32] Miao R, Li X, Wu Y, Wang P, Wang L, Wu G, Wang J, Lv Y, Liu T. A comparison of the roles of $\mathrm{Ca} 2+$ and $\mathrm{Mg} 2+$ on membrane fouling with humic acid: Are there any differences or similarities? Journal of Membrane Science 2017; 545(1 January 2018): 81-7.

[33] Nguyen LAT, Schwarze M, Schomäcker R. Adsorption of non-ionic surfactant from aqueous solution onto various ultrafiltration membranes. Journal of Membrane Science 2015; 493(1 November 2015): 120-33.

[34] Mokri NA, Oh PC, Mukhtar H, Chew TL. Synthesis of high molecular weight polyimide consisting hexafluoroisopropylidene moiety for gas separation. Journal of Mechanical Engineering and Sciences ISSN 2017; 11(4): 2289-4659.

[35] Peeva PD, Million N, Ulbricht M. Factors affecting the sieving behavior of anti-fouling thinlayer cross-linked hydrogel polyethersulfone composite ultrafiltration membranes. Journal of Membrane Science 2012; 390-391(15 February 2012): 99-112.

[36] Basri H, Ismail AF, Aziz M. Microstructure and anti-adhesion properties of PES/TAP/Ag hybrid ultrafiltration membrane. Desalination 2012; 287(15 February 2012): 71-7.

[37] Yu D, Teng M, Chou W, Yang M. Characterization and inhibitory effect of antibacterial PAN-based hollow fiber loaded with silver nitrate 2003; 225(1-2): 115-23.

[38] Sedlarik V, Galya T, Sedlarikova J, Valasek P, Saha P. The effect of preparation temperature on the mechanical and antibacterial properties of poly ( vinyl alcohol )/ silver nitrate fi lms. Polymer Degradation and Stability 2010; 95(3): 399-404.

[39] Zhang DY, Liu J, Shi YS, Wang Y, Liu HF, Hu QL, Su L, Zhu J. Antifouling polyimide membrane with surface-bound silver particles. Journal of Membrane Science 2016; 516(15 October 2016): 83-93.

[40] Wang Y, Yang Q, Shan G, Wang C, Du J, Wang S, Li Y, Chen X, Jing X, Wei Y. Preparation of silver nanoparticles dispersed in polyacrylonitrile nanofiber film spun by electrospinning. Materials Letters 2005; 59(24-25): 3046-9.

[41] Song K, Gao A, Cheng X, Xie K. Preparation of the superhydrophobic nano-hybrid membrane containing carbon nanotube based on chitosan and its antibacterial activity. Carbohydrate Polymers 2015; 130(5 October 2015): 381-7.

[42] Wei D, Sun W, Qian W, Ye Y, Ma X. The synthesis of chitosan-based silver nanoparticles and their antibacterial activity. Carbohydrate Research 2009; 344(17): 2375-82. 
[43] An J, Zhang H, Zhang J, Zhao Y, Yuan X. Preparation and antibacterial activity of electrospun chitosan/poly(ethylene oxide) membranes containing silver nanoparticles. Colloid and Polymer Science 2009; 287(12): 1425-34.

[44] Wu C-S, Hsu Y-C, Liao H-T, Cai Y-X. Antibacterial activity and in vitro evaluation of the biocompatibility of chitosan-based polysaccharide/polyester membranes. Carbohydrate Polymers 2015; 134(10 December 2015): 438-47.

[45] Musee N, Nota N. The antibacterial effects of engineered nanomaterials : implications for wastewater treatment plants $\dagger$. Journal of Environmental Monitoring 2011; 13(5): 1164-83.

[46] Matin A, Khan Z, Zaidi SMJ, Boyce MC. Biofouling in reverse osmosis membranes for seawater desalination: Phenomena and prevention. Desalination 2011; 281(1): 1-16.

[47] Li Q, Mahendra S, Lyon DY, Brunet L, Liga M V, Li D, Alvarez PJJ. Antimicrobial nanomaterials for water disinfection and microbial control: Potential applications and implications. Water Research 2008; 42(18): 4591-602.

[48] Vatanpour V, Shockravi A, Zarrabi H, Nikjavan Z, Javadi A. Fabrication and characterization of anti-fouling and anti-bacterial Ag-loaded graphene oxide/polyethersulfone mixed matrix membrane. Journal of Industrial and Engineering Chemistry 2015; 30(25 October 2015): 342-52.

[49] He L, Dumée LF, Feng C, Velleman L, Reis R, She F, Gao W, Kong L. Promoted water transport across graphene oxide-poly(amide) thin film composite membranes and their antibacterial activity. Desalination 2015; 365(1 June 2015): 126-35.

[50] Duan L, Wang Y, Zhang Y, Liu J. Graphene immobilized enzyme/polyethersulfone mixed matrix membrane: Enhanced antibacterial, permeable and mechanical properties. Applied Surface Science 2015; 355(15 November 2015): 436-45.

[51] Zhang Z, Wu J-J, Su Y, Zhou J, Gao Y, Yu H-Y, Gu J-S. Layer-by-layer assembly of graphene oxide on polypropylene macroporous membranes via click chemistry to improve antibacterial and antifouling performance. Applied Surface Science 2015; 332(30 March 2015): 300-7.

[52] Moritz M, Geszke-Moritz M. The newest achievements in synthesis, immobilization and practical applications of antibacterial nanoparticles. Chemical Engineering Journal 2013; 228(15 July 2013): 596-613.

[53] Goei R, Lim TT. Ag-decorated TiO2 photocatalytic membrane with hierarchical architecture: Photocatalytic and anti-bacterial activities. Water Research 2014; 59(1 August 2014): 20718.

[54] Li JH, Xu YY, Zhu LP, Wang JH, Du CH. Fabrication and characterization of a novel TiO2 nanoparticle self-assembly membrane with improved fouling resistance. Journal of Membrane Science 2009; 326(2): 659-66.

[55] Nor NAM, Jaafar J, Ismail AF, Mohamed MA, Rahman MA, Othman MHD, Lau WJ, Yusof N. Preparation and performance of PVDF-based nanocomposite membrane consisting of $\mathrm{TiO} 2$ nanofibers for organic pollutant decomposition in wastewater under UV irradiation. Desalination 2015; 391: 89-97.

[56] Nguyen A, Zou L, Priest C. Evaluating the antifouling effects of silver nanoparticles regenerated by $\mathrm{TiO} 2$ on forward osmosis membrane. Journal of Membrane Science 2014; 454: 264-71.

[57] Zodrow K, Brunet L, Mahendra S, Li D, Zhang A, Li Q, Alvarez PJJ. Polysulfone ultrafiltration membranes impregnated with silver nanoparticles show improved biofouling resistance and virus removal. Water Research 2009; 43(3): 715-23.

[58] Perez M. The Effects of Silver Nanoparticles on Wastewater Treatment and Escherichia Coli Growth. 2012. 
[59] Pendergast MM, Hoek EMV. A review of water treatment membrane nanotechnologies. Energy \& Environmental Science 2011; 4(6): 1946.

[60] Bong Y., Oh P., Chew T. The effect of amine substituent chain length on POSS/Polysulfone mixed matrix membrane. Journal of Mechanical Engineering and Sciences 2018; 12(1): 3494-504.

[61] Li JH, Shao XS, Zhou Q, Li MZ, Zhang QQ. The double effects of silver nanoparticles on the PVDF membrane: Surface hydrophilicity and antifouling performance. Applied Surface Science 2013; 265: 663-70.

[62] Mollahosseini A, Rahimpour A, Jahamshahi M, Peyravi M, Khavarpour M. The effect of silver nanoparticle size on performance and antibacteriality of polysulfone ultrafiltration membrane. Desalination 2012; 306: 41-50.

[63] Zhang H, Mao H, Wang J, Ding R, Du Z, Liu J, Cao S. Mineralization-inspired preparation of composite membranes with polyethyleneimine-nanoparticle hybrid active layer for solvent resistant nanofiltration. Journal of Membrane Science 2014; 470: 70-9.

[64] Fan Z, Wang Z, Sun N, Wang J, Wang S. Performance improvement of polysulfone ultrafiltration membrane by blending with polyaniline nanofibers. Journal of Membrane Science 2008; 320: 363-71.

[65] Xue Y, Shi W, Zhu B, Gu X, Wang Y, Yan C. Polyethyleneimine-grafted boronate affinity materials for selective enrichment of cis-diol-containing compounds. Talanta 2015; 140: 1-9.

[66] Jia J, Wu A, Luan S. Spectrometry recognition of polyethyleneimine towards heavy metal ions. Colloids and Surfaces A: Physicochemical and Engineering Aspects 2014; 449: 1-7.

[67] Fang X, Li J, Li X, Sun X, Shen J, Han W, Wang L. Polyethyleneimine, an effective additive for polyethersulfone ultrafiltration membrane with enhanced permeability and selectivity. Journal of Membrane Science 2015; 476: 216-23.

[68] Taurozzi JS, Arul H, Bosak VZ, Burban AF, Voice TC, Bruening ML, Tarabara V V. Effect of filler incorporation route on the properties of polysulfone-silver nanocomposite membranes of different porosities. Journal of Membrane Science 2008; 325(1): 58-68.

[69] Eren E, Sarihan A, Eren B, Gumus H, Kocak FO. Preparation, characterization and performance enhancement of polysulfone ultrafiltration membrane using PBI as hydrophilic modifier. Journal of Membrane Science 2015; 475: 1-8.

[70] Harun Z, Jamalludin MR, Basri H, Shohur MF, Rosman N, Yunos MZ. The effect of synthetic silica on ultrafiltration PSf membrane. Jurnal Teknologi (Sciences and Engineering) 2013; 65(4): 121-5.

[71] Mohamad Said KA, George GG, Mohamed Alipah NA, Ismail NZ, Jama'in RL, Mili N, Salleh SF, Mohamed Amin MA, Muslimen R, Yakub I, Mohamed Sutan N. Effect of activated carbon in Polysufone-Polyethyleneimine-Silver composite membrane towards adsorption of chromium $(\mathrm{Cr})$, lead $(\mathrm{Pb})$, silver $(\mathrm{Ag})$ and cadmium $(\mathrm{Cd})$ in synthetic wastewater. Journal of Materials and Environmental Science 2017; 8(10): 3740-6.

[72] Meng J, Zhang X, Ni L, Tang Z, Zhang YY, Zhang YY, Zhang W. Antibacterial cellulose membrane via one-step covalent immobilization of ammonium/amine groups. Desalination 2015; 359: 156-66.

[73] Gao J, Sun S, Zhu W, Chung T. Polyethyleneimine ( PEI ) cross-linked P84 nano fi ltration ( NF ) hollow fi ber membranes for Pb 2 p removal 2014; 452: 300-10.

[74] Ananth a., Arthanareeswaran G, Wang H. The influence of etraethylorthosilicate and polyethyleneimine on the performance of polyethersulfone membranes. Desalination 2012; 287: 61-70.

[75] Mondal A, Mandal B. Synthesis and characterization of crosslinked poly(vinyl alcohol)/poly(allylamine)/2-amino-2-hydroxymethyl-1,3-ropanediol/polysulfone composite membrane for CO2/N2 separation. Journal of Membrane Science 2013; 446: 383-94.

[76] Sile-Yuksel M, Tas B, Koseoglu-imer DY, Koyuncu I. Effect of silver nanoparticle (AgNP) 3823 
location in nanocomposite membrane matrix fabricated with different polymer type on antibacterial mechanism. Desalination 2014; 347: 120-30.

[77] Panda SR, De S. Preparation, characterization and performance of $\mathrm{ZnCl} 2$ incorporated polysulfone (PSF)/polyethylene glycol (PEG) blend low pressure nanofiltration membranes. Desalination 2014; 347: 52-65.

[78] Basri H. Development of Hybrid Antibacterial Membrane By Incorportang Silver Development of Hybrid Antibacterial Membrane By Incorportang Silver Particle As Compatibilizer. 2012.

[79] Li JF, Xu ZL, Yang H, Yu LY, Liu M. Effect of TiO2 nanoparticles on the surface morphology and performance of microporous PES membrane. Applied Surface Science 2009; 255(9): 4725-32.

[80] Ding SH, Chew TL, Oh PC, Ahmad AL, Jawad ZA. Preparation of mixed matrix membrane using cellulose acetate incorporated with synthesized KIT-6 silica. Journal of Mechanical Engineering and Sciences 2018; 12(1): 3505-14. 